\title{
Plasmodium Falciparum and Schistosoma Heamatobium Infections in Pregnant Women Attending Antenatal Clinic in Sekondi-Takoradi Metropolis Western Region Ghana
}

\author{
Article by Verner. N. Orish ${ }^{1}$, Danny flint Yeboah ${ }^{2}$, Ekene Nwaefuna ${ }^{3}$ Richmond \\ Afoakwah ${ }^{4}$ \\ ${ }^{1}$ Department of Microbiology, School of Medicine, University of Health and Allied \\ Sciences, Ho, Volta Region, Ghana \\ ${ }^{2,4}$ Department of Biomedical and Forensic Sciences, School of Biological Sciences \\ University of Cape Coast \\ ${ }^{3}$ Ghana Atomic Energy Commission Accra, Biotechnology and Nuclear Agricultural \\ Research \\ E-mail: orishv@yahoo.com
}

\begin{abstract}
Plasmodium falciparum and Schistosoma hematobium infections are very common parasitic infections that affect pregnant women in the tropics. In this study we evaluated the prevalence and contribution to anemia of Plasmodium falciparum and Schistosoma heamatobium among pregnant women attending antenatal clinic in Sekondi Takoradi Metropolis.

This is across sectional study involving pregnant women attending antenatal clinic in Effia nkwanta regional hospital, Esikado hospital, Takoradi hospital and Jemima Crentsil hospital. Plasmodium falciparum detection and hemoglobin estimation were done from blood samples collected. Urine microscopy was done using the wet mount technique to detect the presence or absence of Schistosoma heamatobium

A total of 872 pregnant women were sampled, 23.4\% (204/872)were infected with plasmodium falciparum infection, 3.3\% (29/872) were infected with Schistosoma heamatobium infection and 34.2\% (298/872) were anemic. Plasmodium falciparum infection had a significant association with anemia $32.2 \% \quad(96 / 298)(P<0.001)$, Schistosoma heamatobium infection had no significant association with anemia, 4.4\% $(6 / 298)(p=0.3)$

Plasmodium falciparum infection was higher and contributes more to anemia in pregnant women than Schistosoma heamatobium infection in this study. However it is very important to screen pregnant women for other parasitic diseases with lower prevalence than malaria to evaluate their burden and contribution to morbidity in pregnancy.
\end{abstract}

\section{Introduction}

Parasitic diseases constitute a significant portion of global infectious disease burden. Occurring worldwide but found mainly in tropical areas of the world and in sub-Sahara Africa where environmental and socio economic factors allow both vectors and pathogens to thrive facilitating spread of disease in the human population [1, 2].

$P$. falciparum is the deadliest of the Plasmodium species that cause severe forms of the disease in malaria endemic west Africa [3, 4]. In this region the risk of infection is higher for children and pregnant woman because of issues of rudimentary and altered immunity respectively $[5,6]$. Pregnant women are particularly susceptible to infection during their first and second pregnancy on account of gravidity dependent immunity [7, 8]. Close to 10,000 pregnant women die from $P$. falciparum from over 25 million malaria infections yearly in sub-Sahara Africa [9, 10]. These infections carry grave consequences for both mother and child.

Schistosma heamtobium (SH) is a trematode that infects millions of people in Sub Sahara Africa[11, 12]. It causes urinaryschistosomiasis characterized frequently by hematuria and less frequently with dysuria [13]. Infection is gotten when infective cercaria penetrate the skin 
of persons who come in contact with fresh water bodies like rivers, lakes and dams[14]. In many places in urban and rural settings in sub-Sahara Africa people use these water bodies as means of recreation like swimming, as a means of livelihood as in fishing and for domestic use as in washing of house old materials [15]. Children of school going age, women and men use these water bodies as a way of life.

In Ghana, pregnant women are exposed to both infections of P.falciparum and SH. Malaria in pregnancy is a serious public health issue constituting 28.1\% of all OPD attendance. 13.1\% of all admission and 9.1 of all maternal deaths [16]. SH in pregnant women on the other hand does not enjoy a robust statistical data like that of malaria, however some studies showed $4.5 \%$ prevalence in two districts in Ghana $[17,18]$. The burden and prevalence of these infections varies in different regions and districts in Ghana. It is very important that more work be done in various regions and districts in Ghana to evaluate the burden of these two parasites in pregnant women. The objectives of this study was (1) to evaluate the prevalence of plasmodium falciparum and SH in pregnant women attending antenatal clinic (2) to evaluate the contribution of plasmodium falciparum and $\mathrm{SH}$ to anemia in pregnant women attending ANC in Sekondi Takoradi metropolis.

\section{Methodology}

\section{Study site}

This study was carried out in the Sekondi-Takoradi metropolis, Ghana. Sekondi-Takoradi, comprising the twin cities of Sekondiand Takoradi, is the administrative capital of the western region of Ghana with a land area of $385 \mathrm{~km} 2$. It is Ghana's fourth largest city and an industrial and commercial Centre with a population of about 335,000. The metropolis is an urban Centre surrounded by towns and villages. Temperatures are high with an average of 22 ${ }^{\circ} \mathrm{C}$. It has a mean annual rainfall of $2.350 \mathrm{~mm}$, which is experienced heavily in May and June with the minor rains occurring between September and October.

\section{Study population and design}

Pregnant women attending their antenatal care (ANC) visits were strategically sampled from four hospitals in the metropolis with the intention of recruiting pregnant women from sub-urban and rural communities of the city. These hospitals included Effia- Nkwanta Regional Hospital, Essikado Hospital, Takoradi Hospital and Jemima Crentsil Hospital. This cross-sectional study was carried out from the month of January to the month of October, 2010. Each facility was visited once every week on their routine antenatal days. Pregnant women, cross-checked with ultra-sound or with clinical evidence of pregnancy, were included in the study while pregnant women with significant bleeding were excluded from the study.

\section{Questionnaire administration}

Each consenting pregnant woman was asked of her demographic characteristics, education and occupational history, past and present obstetrics history. History of fever and any other illness during the pregnancy were asked.

\section{Sample collection}

About $5 \mathrm{ml}$ of venous blood were collected from the pregnant women by a trained laboratory technician from the median cubitalvein. Blood samples were collected into an EDTA bottle and temporarily stored in an ice chest and were transported to a designated reference laboratory for same day analysis and storage. About $10 \mathrm{ml}$ of urine was collected from the pregnant women in a clean container

\section{Malaria diagnosis}

Laboratory diagnosis of malaria was performed using fast RAPID response antibody kit (Premier Medical Corporation Ltd). The brand of the RAPID response kit was specific for the detection of P.falciparum antigens. The presence of two lines in the text kit well indicated 
positive for $P$. falciparum malaria. The RAPID response kit contained a membrane strip precoated with monoclonal antibody specific for histidinerich protein 2 antigen of $P$. falciparum. For proper confirmation of malaria parasites, thick and thin smear with Geimsa staining were performed and examined microscopically using 100 power fields under oil immersion. Malaria parasites were counted against 200 leukocytes, read independently by two competent microscopists and where they had discordances, a third microscopist reassessed the slide. Malaria diagnosis was defined on the identification of any asexual blood stages of $P$. falciparum species in the thick and thin smears while a slide was pronounced negative when 100 high power fields have been examined using x100 oil immersion objective lens.

\section{Urinary schistosomiasis diagnosis}

$\mathrm{SH}$ detection was done using microscopy of urine sediments. About $10 \mathrm{ml}$ of urine was collected from the pregnant women during their antenatal visits at the hospital or clinic premises. Urine samples were centrifuged and sediments examined under the microscope and eggs of SH counted directly. This was done by two microscopists and discordant results were resolved by a third microscopist.

\section{Haemoglobin estimation}

Haemoglobin estimation was performed using cyanmet hemoglobin method [19] Anaemia was defined based on WHO criteria haemoglobin levels of $<11 \mathrm{~g} / \mathrm{dL}[20]$.

\section{Ethical clearance}

Ethical clearance for the study was gotten from the Ghana Health Service Ethics Review Committee. Written informed consents were received from the recruited pregnant women.

\section{Data analysis}

Data and statistical analyses were performed using IBM SPSS Statistics version 17.0 (SPSS Inc., IL USA). Frequency distributions were done for all the characteristics of the pregnant women in the study (age, marital status, occupation, education, malaria and HIV status, anaemia, gravidity). These characteristics of the pregnant women were further analyzed using either Pearson $\chi^{2}$ tests or Exact $\chi^{2}$ test and ANOVA for the comparison of mean.95\% confidence interval (CI) were used to measure the strength of the association and $\mathrm{P}$ $<0.05$ was considered statistically significant.

\section{Result}

A total of eight hundred and seventy-two pregnant women were sampled for this study. Table 1 shows the characteristics of these pregnant women. 298 (34.2\%) of the women were anaemic, 204 (23.4\%) had Plasmodium falciparum infection while 29 (3.3\%) had Schistosoma heamatobium infection. Majority of the women were married (93.1\%), attended secondary school (61.4\%) and were between the ages of 20-30s (60.6\%).

Table 2stratifies the pregnant women based on their malaria status. There was no significant association $(\mathrm{p}=0.349)$ between the level of education and Plasmodium infection. There was also no significant association $(\mathrm{p}=0.9)$ between $\mathrm{SH}$ and Plasmodium falciparum infection. However age was significantly associated $(\mathrm{P}=0.02)$ with Plasmodium falciparum infection as the prevalence of Plasmodium infection was higher among pregnant women between the ages 13-19. Anemia also had a significant association $(\mathrm{p}<0.001)$ with Plasmodiumfalciparum infection.

Table 3 stratifies the pregnant women based on their SH infection status. There were no significant association seen between education and maternal anemia and age of the pregnant women with SH infection.

Table 4 stratifies the pregnant women based on their hemoglobin level. There was an association between anemia and Plasmodium falciparum infection as there was a significant difference $(\mathrm{p}<0.001)$ between Plasmodium prevalence among pregnant women with anemia 
and pregnant women without anemia. There was no association noted between with $\mathrm{SH}$ and the hemoglobin levels of the pregnant women.

\section{Discussion}

Plasmodium falciparum and SH infections are common parasitic infection in sub-Sahara Africa. In this study we looked at their prevalence and their burden in contributing to anemia in pregnant women attending ANC in Sekondi-Takoradi metropolis.

In this study the prevalence of $P$. falciparum infection was very much higher than that of $\mathrm{SH}$. Though both infections have same spatial distribution in endemic areas, SH have a more focal distribution and complex transmission cycle[21]. While P.falciparum requires female Anopheles mosquito as a vector for transmission to humans in the comfort of their homes, $\mathrm{SH}$ on the hand requires human-cercaria contact in a susceptible fresh water habitat. SekondiTakoradi is predominantly a coastal city with mainly salty sea water. However very few suburbs surrounding the metropolis have rivers that are potential source of SH infection. The paucity of appropriate fresh water bodies in the metropolis might explain the low prevalence of 3.3\% compared to two other studies done in Bawku in the northern region and damaged district in Accra Ghana that both had a prevalence of 4.5\% [17, 18].

P.falciparum infection was found to be associated with the age of the pregnant women as the prevalence was significantly higher in teenage pregnancy. This finding is in agreement with a study done in the northern part of Ghana 22]. Teenagers are basically still developing their immunity and hence with pregnancy there is a further depression of their immune system compared to their adult counterpart [23].

$P$. falciparum infection contributed more to anaemia than $\mathrm{SH}$ infection in this study. However, it is a well-established fact $\mathrm{SH}$ causes anemia and negative birth outcomes in pregnant women $[17,24,25]$. The insignificant contribution to anemia in this study might be due to the low prevalence of SH in this study. Despite the higher prevalence of $P$. falciparum in this study, it has been known to cause anemia in infected individuals especially in pregnant women and children [4, 26, 27].

\section{Conclusion}

While the prevalence of $P$. falciparum infection in pregnancy remains high in SekondiTakoradi just like all other parts of Ghana, that of SH infection is quite low, possibly due to the paucity of suitable fresh water habitats. Due to its low prevalence, SH infection contributes insignificantly to anaemia in pregnant women in the metropolis. Malaria, on the other hand, is still a big issue for pregnant women in Sekondi-Takoradi and other endemic areas, contributing greatly to anaemia. Notwithstanding, screening for other parasitic diseases to evaluate their burden and their contribution to morbidity in pregnant women is still very important

Table 1. General characteristics of pregnant women

\begin{tabular}{lrcc}
\hline Characteristics & & $\begin{array}{c}\text { Frequency } \\
(\mathbf{n}=\mathbf{8 7 2})\end{array}$ & $\begin{array}{c}\text { Percentage } \\
\mathbf{( \% )}\end{array}$ \\
\hline Age (Years) & $15-19$ & 107 & \\
& $20-29$ & 529 & 60.4 \\
& $30-29$ & 221 & 25.4 \\
& $40-49$ & 15 & 1.8 \\
Marital Status & Married & 812 & 93.1 \\
& Single & 60 & 6.9 \\
Education & None & 171 & 19.6 \\
& Primary & 128 & 14.7
\end{tabular}


Texila International Journal of Public Health

Volume 4, Issue 4, Dec 2016

\begin{tabular}{lrcc} 
& Secondary & 535 & 61.4 \\
Occupation & Tertiary & 38 & 4.4 \\
& & & \\
& Seamstress/Hairdresser & 238 & 27.3 \\
& Trader & 367 & 42.1 \\
Farmer & 132 & 15.1 \\
Malaria Status & Food vendor & 135 & 15.6 \\
& & & \\
Haemoglobin & Positive & 204 & 23.4 \\
& Negative & 668 & 76.6 \\
S hematobium & & & \\
& Anaemia & 298 & 34.2 \\
& Normal & 574 & 65.8 \\
& & & \\
& Present & 29 & 3.3 \\
\hline
\end{tabular}

Table 2. Characteristics of pregnant women stratified by malaria status

\begin{tabular}{|c|c|c|c|c|}
\hline Characteristics & & $\mathrm{P}$ - value & $\begin{array}{l}\text { Malaria } \\
\text { Positive (\%) }\end{array}$ & $\begin{array}{l}\text { Malaria Negative } \\
\text { (\%) }\end{array}$ \\
\hline \multirow[t]{5}{*}{ Education } & & 0.349 & & \\
\hline & None & & 45 (26.3) & 126 (73.7) \\
\hline & Primary & & 33 (25.9) & 95 (74.2) \\
\hline & Secondary & & 115 (21.4) & $420(78.5)$ \\
\hline & Tertiary & & $6(15.8)$ & $32(84.2)$ \\
\hline \multirow[t]{3}{*}{ Age of woman } & & 0.02 & & \\
\hline & $<19$ years $(107)$ & & 37 (34.6) & $70(65.4)$ \\
\hline & $>20$ years $(765)$ & & $162(21.2)$ & 597 (78.0) \\
\hline \multirow[t]{3}{*}{ Maternal anaemia } & & $<0.001$ & & \\
\hline & $<11 \mathrm{~g} / \mathrm{dl}$ & & 96 (32.2) & 202 (67.8) \\
\hline & $>11 \mathrm{~g} / \mathrm{dl}$ & & 108 (18.8) & $465(81.0)$ \\
\hline \multirow{3}{*}{ S. hematobium } & & 0.9 & & \\
\hline & Present & & $6(20.6)$ & $23(79.3)$ \\
\hline & Absent & & $198(23.5)$ & 645 (76.5) \\
\hline
\end{tabular}

Table 3. Characteristics of pregnant women stratified by S.H status

\begin{tabular}{lllll}
\hline Characteristics & & P - value & S.H. Present (\%) & S.H absent (\%) \\
\hline Education & & 0.57 & & \\
& None & & $4(2.3)$ & $167(97.7)$ \\
& Primary & & $5(3.9)$ & $123(96.1)$ \\
& Secondary & & $20(3.7)$ & $515(96.3)$ \\
& Tertiary & & $0(0)$ & $38(100)$ \\
Age of woman & & 0.13 & & \\
& $<19$ years (107) & & $6(5.6)$ & $101(94.39)$ \\
Maternal anaemia & $>$ 20 years (765) & & $23(3.0)$ & $742(97.0)$ \\
& $<11$ g/dl & 0.2 & $13(4.4)$ & $285(95.6)$ \\
& $>11$ g/dl & & $16(2.8)$ & $558(97.2)$ \\
\hline
\end{tabular}


Table 4: Baseline characteristics of the pregnant women stratified by haemoglobin level

\begin{tabular}{lccc}
\hline Characteristics & $\begin{array}{l}\text { Hemoglobin }(<11 \mathrm{~g} / \mathrm{dL}) \\
(\mathrm{n}=298)\end{array}$ & $\begin{array}{l}\text { Haemoglobin }(>11 \mathrm{~g} / \mathrm{dL}) \\
(\mathrm{n}=574)\end{array}$ & P value \\
\hline Education & $57(19.9)$ & $109(19.7)$ & \\
$\quad$ None & $43(15)$ & $77(13.9)$ & 0.11 \\
Primary & $182(63.4)$ & $338(61.1)$ & \\
Secondary & $5(1.7)$ & $29(5.2)$ & \\
$\quad \begin{array}{l}\text { Tertiary } \\
\text { Occupation }\end{array}$ & & $286(94.7)$ & \\
$\quad$ Farmer/trader & $149(96.8)$ & $9(3)$ & 0.27 \\
Civil service & $1(0.6)$ & $7(2.3)$ & \\
$\quad \begin{array}{l}\text { Teacher } \\
\text { Malaria }\end{array}$ & $4(2.6)$ & & \\
infection & & $107(18.7)$ & \\
$\quad$ Negative & $204(68)$ & $16(2.8)$ & 0.3 \\
Positive & $96(32)$ & $558(97.2)$ & \\
S hematobium & $13(4.4)$ & & \\
$\quad$ Present & $285(95.6)$ & & \\
Absent & & & \\
\hline
\end{tabular}

\section{List of abbreviations}

SH: Schistosomaheamtobium

EDTA: Ethylenediaminetetraacetic acid

ANC: antenatal care

OPD: outpatient department

\section{Declaration}

\section{Competing interest}

Authors declare that they have no competing interest

\section{Authors' contributions}

ORISH Verner conceived, planned, executed the study and drafted the manuscript as well as analysis of data; Richmond Afoakwah, helped in drafting the manuscript; Ekene Nwaefuna and Danny flint Yeboah edited /reviewed and revised the manuscript. All authors have read and approved the final manuscript.

\section{References}

[1]. Artavanis-Tsakonas, K., Tongren, J. E., \& Riley, E. M. (2003). The war between the malaria parasite and the immune system: immunity, immunoregulation and immunopathology. Clinical \& Experimental Immunology, 133(2), 145-152.

[2]. Adegnika, A. A., Ramharter, M., Agnandji, S. T., AtebaNgoa, U., Issifou, S., Yazdanbahksh, M., \& Kremsner, P. G. (2010). Epidemiology of parasitic co-infections during pregnancy in Lambaréné, Gabon. Tropical Medicine \& International Health, 15(10), 1204-1209.

[3]. Brooker, S. (2007). Spatial epidemiology of human schistosomiasis in Africa: risk models, transmission dynamics and control. Transactions of the Royal Society of Tropical Medicine and Hygiene, 101(1), 1-8.

[4]. Beeson, J. G., Brown, G. V., Molyneux, M. E., Mhango, C., Dzinjalamala, F., \& Rogerson, S. J. (1999). Plasmodium falciparum isolates from infected pregnant women and children are associated with distinct adhesive and antigenic properties. Journal of infectious diseases, 180(2), 464-472.

[5]. Bhaskaram, P., Balakrishna, N., Radhakrishna, K. V., \& Krishnaswamy, K. (2003). Validation of hemoglobin estimation using Hemocue. The Indian Journal of Pediatrics, 70(1), 25-28. 
[6]. Clerk, C.A., Bruce, J., Greenwood, B. \& Chandramohan, D. 2009. The epidemiology of malaria among pregnant women attending antenatal clinics in an area with intense and highly seasonal malaria transmission in northern Ghana. Trop Med Int Health. 14(6):688-95.

[7]. Chitsulo, L., Engels, D., Montresor, A., \& Savioli, L. (2000). The global status of schistosomiasis and its control. Actatropica, 77(1), 41-51.

[8]. DeMaeyer, E. M., Hallberg, L., Gurney, J. M., Sood, S. K., Dallman, P., Srikantia, S. G., \& World Health Organization. (1989). Preventing and controlling iron deficiency anaemia through primary health care: a guide for health administrators and programme managers.

[9]. DATE, E. A. N. (2014). I hereby declare that this submission is my own work towards the MPhil and that to the best of my knowledge, it contains no material previously published by another person nor material which has been accepted for the award of any other degree of the university, except where due acknowledgement has been made in the text (Doctoral dissertation, KWAME NKRUMAH UNIVERSITY OF SCIENCE AND TECHNOLOGY, KUMASI).

[10]. Friedman, J. F., Mital, P., Kanzaria, H. K., Olds, G. R., \& Kurtis, J. D. (2007). Schistosomiasis and pregnancy. Trends in parasitology, 23(4), 159-164.

[11]. Froeschke, G., Harf, R., Sommer, S., \& Matthee, S. (2010). Effects of precipitation on parasite burden along a natural climatic gradient in southern Africa-implications for possible shifts in infestation patterns due to global changes. Oikos, 119(6), 1029-1039.

[12]. Gething, P. W., Patil, A. P., Smith, D. L., Guerra, C. A., Elyazar, I. R., Johnston, G. L., ... \& Hay, S. I. (2011). A new world malaria map: Plasmodium falciparum endemicity in 2010. Malaria journal, 10(1), 1.

[13]. Guyatt, H. L., \& Snow, R. W. (2001). The epidemiology and burden of Plasmodium falciparumrelated anemia among pregnant women in sub-Saharan Africa. The American journal of tropical medicine and hygiene, 64(1 suppl), 36-44.

[14]. Greenwood, B., Marsh, K., \& Snow, R. (1991). Why do some African children develop severe malaria?. Parasitology today, 7(10), 277-281.

[15]. Guyatt, H. L. \& Snow, R. W. (2004). Impact of malaria during pregnancy on low birth weight in sub-Saharan Africa. Clin Microbiol Rev. 17(4), 760-9. Review.

[16]. Gray, D. J., Ross, A. G., Li, Y. S., \& McManus, D. P. (2011). Diagnosis and management of schistosomiasis. BMJ, 342(may16_2), d2651-d2651.

[17]. Ghana health service, (2005). Malaria in Pregnancy Training manual for Health professionals.

[18]. Hotez, P. J., \& Kamath, A. (2009). Neglected tropical diseases in sub-saharan Africa: review of their prevalence, distribution, and disease burden. PLoSNegl Trop Dis, 3(8), e412.

[19]. Orish, V. N., Onyeabor, O. S., Boampong, J. N., Aforakwah, R., Nwaefuna, E., \& Iriemenam, N. C. (2012). Adolescent pregnancy and the risk of Plasmodium falciparum malaria and anaemia-A pilot study from Sekondi-Takoradi metropolis, Ghana. Actatropica, 123(3), 244-248.

[20]. Pullan, R., \& Brooker, S. (2008). The health impact of polyparasitism in humans: are we underestimating the burden of parasitic diseases?. Parasitology, 135(07), 783-794.

[21]. Stevens, G. A., Finucane, M. M., De-Regil, L. M., Paciorek, C. J., Flaxman, S. R., Branca, F., ... \& Nutrition Impact Model Study Group. (2013). Global, regional, and national trends in haemoglobin concentration and prevalence of total and severe anaemia in children and pregnant and non-pregnant women for 1995-2011: a systematic analysis of population-representative data. The Lancet Global Health, 1(1), e16-e25.

[22]. Siegrist, D., \& Siegrist-Obimpeh, P. (1992). Schistosomahaematobium infection in pregnancy. Actatropica, 50(4), 317-321.

[23]. Tatem, A. J., Smith, D. L., Gething, P. W., Kabaria, C. W., Snow, R. W., \& Hay, S. I. (2010). Ranking of elimination feasibility between malaria-endemic countries. The Lancet, 376(9752), 15791591.

[24]. Takougang, I., Meli, J., Fotso, S., Angwafo 3rd, F., Kamajeu, R., \& Ndumbe, P. M. (2003). Hematuria and dysuria in the self-diagnosis of urinary schistosomiasis among school-children in Northern Cameroon. African journal of health sciences, 11(3-4), 121-127. 
Texila International Journal of Public Health

Volume 4, Issue 4, Dec 2016

[25]. Uneke, C. J. (2007). Impact of Placental Plasmodium falciparum Malaria on Pregnancy and Perinatal Outcome in Sub-Saharan AfricaI: Introduction to Placental Malaria Yale. J Biol Med. 80(2), 39-50.

[26]. WHO. (2003). The africa malaria report. Geneva (WHO/CDS/MAL/2003.1093).

[27]. Wilkins, H. A., Goll, P. H., Marshall, T. D. C., \& Moore, P. J. (1984). Dynamics of Schistosomahaematobium infection in a Gambian community. I. The pattern of human infection in the study area. Transactions of the Royal Society of Tropical Medicine and Hygiene, 78(2), 216-221. 